\title{
Degradabilidade ruminal do farelo de soja e do feno de coast-cross, com bovinos fistulados em dietas com diferentes proporções volumoso/concentrado
}

\author{
Ruminal degradability of soybean oil meal and coast-cross \\ hay, with canulated steers fed different ratios of roughage- \\ concentrate in their diets
}

CORRESPONDENCE TO: Cartas de Souse Luad Departamento de Criagdo de Ruminantas $\theta$ Alimentagato Animal Faculdade de Medicina Velerinárla $\theta$ Zootecnia de USP

Av. Duque de Caxias Norte, 225 Cabca Pastal 23

13630-970 - Pirassununga - SP Brasil

o-mall: terassi@usp.tor

1 - Faculdade de Medicina Veterinária e Zootecnia da USP Pirassununga - SP

\author{
Adriana Ramenzoni SEFRIN'; Carlos de Sousa LUCCI'; Laércio MELOTTI'
}

\section{RESUMO}

\begin{abstract}
Este trabalho teve por objetivo avaliar a degradabilidade ruminal da matéria seca (MS) e proteína bruta (PB) do farelo de soja e da MS e fibra detergente neutro (FDN) do teno de coast-cross, segundo a técnica de sacos de náilon in situ, em tratamentos com diferentes proporçōes de volumoso: $A=40 \%, B=60 \%, C=80 \%$ e $D=100 \%$ de feno. Os animais utilizados eram 16 bovinos machos, dotados de fístulas de rúmen, para os quais foram sorteados os quatro tratamentos, em dietas isonitrogenadas, dentro de um delineamento de blocos ao acaso. Quanto ao farelo de soja, a degradabilidade da MS com 24 horas de incubação no rúmen aumentou linearmente ( $p$ $<0,05$ ), à medida que se elevou a quantidade de volumoso na dieta e variou de $77,9 \%$ a $88,1 \%$, enquanto a PB nāo apresentou diferenças significativas nos diversos intervalos de tempo e variou de $81,7 \%$ a $90,4 \%$, com 24 horas de incubação. Quanto ao feno, as degradabilidades da MS e FDN apresentaram menores valores $(p<0,01)$ no tratamento com menor nível de volumoso na ração $(40 \%)$. O número de protozoários total no fluido do rúmen mostrou uma regressāo quadrática $(p<0,01)$, sendo o menor valor referente ao tratamento com $40 \%$ de volumoso.
\end{abstract}

UNITERMOS: Digestibilidade; Bovinos; Fistula; Feno; Farelo de soja.

\section{INTRODUÇÃO}

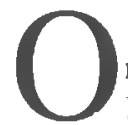
pH do rúmen apresenta menores valores quando se fornecem dietas pobres em volumoso (Wohlt et al. ${ }^{360}, 1973$; Lucci et al. ${ }^{21}, 1982$; Barrio et al. ${ }^{4}$. 1985; Barrio et al. ${ }^{3}$, 1986; Robinson; Kennelly ${ }^{31} 1991$ a; Kennedy; Bunting ${ }^{14}$, 1992).

Vários trabalhos provaram que a degradabilidade da MS e fibra das forragens, no rúmen. decresce com a diminuição da proporção de volumosos ná ração (Chimwano et al. ${ }^{6}, 1976$; Lindberg $^{16}, 1981 a ;$ Uden $^{35}, 1984$; Rode et al. $.^{32}, 1985$; Flachowsky; Schneider ${ }^{4}, 1992 ;$ Petit $\left.^{24}, 1992\right)$. Contudo, Poore et al..$^{30}$ (1990) só encontraram diminuição na degradabilidade ruminal da FDN quando os volumosos constituíram $10 \%$ da dieta. No que tange aos concentrados, com raçōes contendo menores proporções de volumosos, Flachowsky; Schneider" ${ }^{\prime}(1992)$ registraram aumento na degradabilidade destes alimentos, mas Susmel er al..$^{33}$ (1989), contrariamente, indicaram decréscimo na degradabilidade.

A técnica mais utilizada para medir a degradabilidade dentro do rúmen é a dos sacos de náilon in situ (Hopson et al. ${ }^{12}$, 1963; Mehrez; Orskov²1, 1977; Orskov et al. ${ }^{27}$, 1980; MichaletDoreau; Ould-Bah"2.3, 1992).

No tocante à microbiota do rúmen, Thompson; Moran ${ }^{34}$ (1986) encontraram, em proporçōes mais baixas de volumosos, diminuição da atividade celulolítica da microflora total do rúmen e da taxa de degradação no órgão. Para Miller; Muntifering ${ }^{24}$ (1985), a diminuição da digestibilidade da fibra, pelo fornecimento de dietas mais pobres em volumosos, é resultante da reduçāo da atividade celulolítica no rúmen dadas as condiçōes de acidez associadas à fermentação rápida do amido presente nos concentrados.

Contrariamente, Zhao et al. ${ }^{37}$ (1993) verificaram que o aumento do volumoso na dieta causou redução significativa na degradabilidade da MS e PB de forragens.

Boer et al..$^{5}(1987)$ definiram que a degradabilidade da PB do farelo de soja foi $55,1 \%, \operatorname{com} 8$ horas de incubaçāo; Kirkpatrick; Kennelly ${ }^{15}$ (1987) registraram que a degradabilidade da MS e da PB do farelo de soja foram respectivamente $59,9 \%$ e $60,2 \%$, em dieta com 16,5\% de PB; Ha; Kennelly" (1984) relataram degradabilidade da PB do farelo de soja igual a $53,6 \%$.

Este trabalho procura encontrar resultados que auxiliem a definir melhor a influência de diferentes proporçōes concentrados/volumosos sobre a degradabilidade da proteína da matéria seca e da fibra dos diversos alimentos utilizados na raçāo; e também avalia $\mathrm{pH}$ e número de protozoários do rúmen, nas condiçōes mencionadas.

\section{MATERIAL E MÉTODOS}

O experimento foi conduzido nas dependências da Faculdade de Medicina Veterinária e Zootecnia da Universidade de São Paulo. Quatro tratamentos estudaram a degradabilidade ruminal da MS e PB do farelo de soja e da MS e FDN do feno de coast-cross (Cynodon dactylon, L.) em dietas com diferentes proporçōes de volumoso: $A=40 \%, B=60 \%, C=80 \%$ e $D=100 \%$ de volumoso (feno) na ração.

Além do feno de coast-cross foram utilizados como concentrados o milho (Zea mays, L.) na forma de grãos e o farelo de soja (Glycine max, L; Merrill), balanceando-se as rações segun- 
do as normas do $\mathrm{NRC}^{25}$ (1989) para bovinos de leite, de forma que permanecessem isonitrogenadas.

Foram utilizados 16 bovinos mestiços europeu-zebu, machos castrados, sendo 8 deles com peso médio de $200 \mathrm{~kg}$ e os outros $8 \mathrm{com}$ peso médio de $400 \mathrm{~kg}$, todos providos de cânulas ruminais.

No tratamento $\mathrm{D}$, foram ministrados via fístula ruminal 8,0 $\mathrm{g}$ de uréia para os animais de $200 \mathrm{~g} \mathrm{e} 40 \mathrm{~g}$ para os de $400 \mathrm{~kg}$, duas vezes ao dia, na forma líquida, com o fim de atender as exigências protéicas; ainda foram fornecidos, concomitantemente, $500 \mathrm{~g}$ de melaço e $40 \mathrm{~g}$ de sulfato de cálcio. Suplementação mineral foi feita com $70 \mathrm{~g}$ de uma mistura comercial.

Foi utilizada a técnica de sacos de náilon in situ, conforme descrito por Mehrez; Orskov ${ }^{21}$ (1977), em tempos de incubação de $0 \mathrm{~h}$ a $48 \mathrm{~h}$ e de $0 \mathrm{~h}$ a $96 \mathrm{~h}$, para medir a MS e a PB do farelo de soja, MS e FDN do feno, respectivamente.

As amostras incubadas foram analisadas quimicamente segundo Goering; Vansoest ${ }^{10}(1970)$; $\operatorname{AOAC}^{2}(1980)$.

Os dados de degradabilidade foram ajustados para o modeIo proposto por Orskov; McDonald ${ }^{28}$ (1979): $\mathrm{p}$ = a + b (1-e-ct), e a degradabilidade efetiva foi calculada conforme A.F.R.C.' (1992).

Após a retirada do último saco de náilon, foram introduzidos via fístula ruminal, $150 \mathrm{~g}$ de polietilenoglicol (PEG) nos animais com $200 \mathrm{~kg}$ e $300 \mathrm{~g}$ para os de $400 \mathrm{~kg}$, diluídos em água destilada. seguindo-se o método descrito por Hyden ${ }^{13}$ (1956). Foi feita ainda contagem de protozoários, segundo Dehorithy ${ }^{8}$ (1977), e medição do pH.

O delineamento estatístico foi o de blocos ao acaso, segundo Cochran; $\operatorname{Cox}^{7}$ (1957), com 4 tratamentos, dois blocos (com 8 animais de $200 \mathrm{~kg}$ e com 8 de $400 \mathrm{~kg}$ de peso), com duas repetiçōes para cada tratamento dentro do bloco.

\section{RESULTADOS E DISCUSSÃO} Tab. 1.

A ingestão de feno, concentrados e MS total encontra-se na

O consumo de MS esteve muito próximo de $2 \mathrm{~kg} / 100 \mathrm{~kg}$ de peso, no bloco com bovinos de $200 \mathrm{~kg}$ de peso, e de $1,5 \mathrm{~kg} / 100$ $\mathrm{kg}$, no bloco com animais de $400 \mathrm{~kg}$. Os bovinos consumiram quantidades semelhantes de $\mathrm{PB}$, os valores do $\mathrm{NRC}^{25}$ (1989) indicam de $573 \mathrm{~g}$ a $629 \mathrm{~g} / \mathrm{dia}$, para $200 \mathrm{~kg}$ de peso e $0,947 \mathrm{~kg} / \mathrm{dia}$ para $40(0 \mathrm{~kg}$. Os resultados da degradabilidade da MS do farelo de soja nos diferentes tempos de incubação ruminal e os dados de degradabilidade efetiva com taxa de efluxo igual a 0,035 constam da Tab. 2.

As taxas de degradabilidade de MS do farelo de soja aumentaram com o incremento de volumoso na ração, mas a regressão linear só foi significativa às 24 horas de incubação $(p<0,05)$, concordando com os dados de Lindberg ${ }^{17}$ (1981b), Lindberg ${ }^{18}$ (1981c); Barrio et al. ${ }^{4}$ (1985): Barrio et al. ${ }^{3}$ (1986). Mas, de acordo com Petit ${ }^{29}$ (1992), o nível de concentrados na dieta não influi na degradaçāo de MS das diversas fontes protéicas.

No caso da $\mathrm{PB}$, não foram encontrados valores significativos para as diferenças entre tratamentos, divergindo de Lindberg $^{17}$ (1981b); Barrioet al. ${ }^{3}$ (1986); Susmel et al. ${ }^{33}$ (1989); Petit ${ }^{29}$ (1992), os quais observaram elevação na degradabilidade efetiva da proteína de suplementos protéicos, quando as dietas apresentam maiores quantidades de volumosos.
As taxas de degradabilidade de PB do farelo de soja estão conforme os resultados citados na literatura (Ha; Kennelly ${ }^{11}, 1984$; Boer et al. ${ }^{5}, 1987$; Kirkpatrick; Kennelly ${ }^{15}, 1987$; Susmel et al..$^{33}$, 1989).

O desaparecimento de $\mathrm{N}$ do farelo de soja pode ter recebido influência da fonte nitrogenada das dietas, já que no tratamento D empregou-se uréia e nos demais, farelo de soja (Loerch et $\left.a l .{ }^{19}, 1983\right)$. A quantidade de milho na ração também é fator influente na degradação do $\mathrm{N}$ (Locrch et al. $.^{19}, 1983$ ) e este cereal entrou com $5,0 \%$ a $55,8 \%$ das dietas A, B e C.

$\mathrm{Na}$ Tab. 3 estão os resultados da degradabilidade ruminal da MS e da FDN do feno nos diversos tempos de incubação e dados de degradabilidade efetiva com taxa de saída ruminal igual a 0,035 .

Resultados diferentes entre tratamentos ocorreram a partir das 24 horas de incubação, conforme indicado por Hopson $e t$ al. ${ }^{12}$ (1963). As regressões significativas indicaram menor degradabilidade da MS do feno no tratamento A (40\% de volumoso). Também Flachowsky; Schneider" (1992) observaram diferenças significativas, com aumento acentuado na degradabilidade da MS, à medida que se aumentava o volumoso na alimentação, da mesma forma que Chimwano et al. ${ }^{6}(1976)$ e Zhao et al..$^{37}$ (1993), e estes últimos mostraram correlação positiva $(r=0,996)$ entre a degradabilidade da proteína e o desaparecimento da MS das plantas forrageiras. Contudo, Lindberg ${ }^{17}$ (1981b) não encontrou diferenças significativas na degradabilidade da MS do feno, entre vários níveis de volumosos na ração.

A degradabilidade da fibra (FDN) do feno, no rúmen, mostrou valores estatisticamente diferentes entre tratamentos, permitindo afirmar que sua degradação, como também ocorreu com a MS do feno, foi inferior para o tratamento A ( $40 \%$ de volumoso), em relação aos demais, mas aumentou com proporções mais elevadas de volumosos nas dietas. Os mesmos resultados foram encontrados por Hopson et al. ${ }^{12}$ (1963); Chimwano et al. ${ }^{6}$ (1976); Lindberg ${ }^{17}$ (1981b); Uden ${ }^{35}$ (1984); Rode et al. ${ }^{32}$ (1985); Miller; Muntifering ${ }^{24}$ (1985); Thompson; Moran $^{34}$ (1986); Kennedy; Bunting ${ }^{14}$ (1992). Já Poore et al..$^{\text {3) }}(1990)$ registraram diminuição) acentuada na degradabilidade ruminal da fibra $(p<0,05)$, apenas quando o volumoso constitui $10 \%$ da dieta.

Thompson; Moran ${ }^{34}$ (1986) descrevem que a penetração de micróbios do rúmen para o interior dos sacos é muito mais rápida em dietas com maiores proporçōes de volumoso, o que explicaria a maior degradabilidade encontrada para as mesmas.

A Tab. 4 apresenta os resultados de $\mathrm{pH}$ do líquido ruminal, do seu volume e turn-over, bem como da concentração de protozoários existentes.

Os valores de $\mathrm{pH}$ e de volume ruminal não apresentaram diferenças estatísticas entre os tratamentos, sendo semelhantes aos encontrados por Susmel et al. ${ }^{33}$ (1989). Outros autores detectaram aumento do volume (Lucci et al. ${ }^{20}, 1982$ ) e queda do $\mathrm{pH}$ ruminal (Lucci et al. ${ }^{20}, 1982$; Barrio et al. ${ }^{4}, 1985$; Barrio et al. ${ }^{3}$, 1986; Poore et al. ${ }^{30}, 1990$; Kennedy; Bunting ${ }^{14}$, 1992; Zhao et $\left.a l^{37}, 1993\right)$ quando aumentaram a proporção de concentrados na matéria seca das dietas.

Wohlt et al..$^{36}$ (1973) relatam que o aumento do $\mathrm{pH}$ do rúmen provoca aumento na solubilidade da proteína de soja e, portanto, maior taxa de degradabilidade da mesma, mas, para que tal fato ocorra, a variação de $\mathrm{pH}$ deve ser de até 2,0 pontos. 


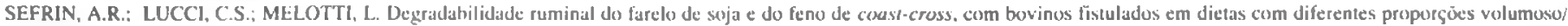
concentrado. Braz. J. vet. Kes. anim. Sci. Säo Paulo, v.34, n. 1. p.31-36. 1997.

Os valores de turn-over do líquido ruminal foram semelhantes aos encontrados por Poore et al. ${ }^{30}(1990)$ e Kennedy; Bunting ${ }^{14}$ (1992). Rode et al. ${ }^{32}$ (1985) observaram aumento linear da taxa de turn-over ruminal, quando elevaram a quantidade de volumoso na dieta $(p<0,05)$.

As concentraçōes de protozoários no líquido ruminal dife- rentes, com maior número destes microorganismos nas dietas mais ricas em volumosos até a proporçāo de $80 \%$, e queda quando nāo houve concentrado na ração (tratamento D). Outros autores (Lucci et al. ${ }^{20}$, 1982) trabalharam com bactérias, determinando maior concentração das mesmas com o emprego de menor proporção de volumosos na dieta.

Tabela 1

Ingestäo diária de íeno. concentrados e MS total. Pirassununga, 1990.

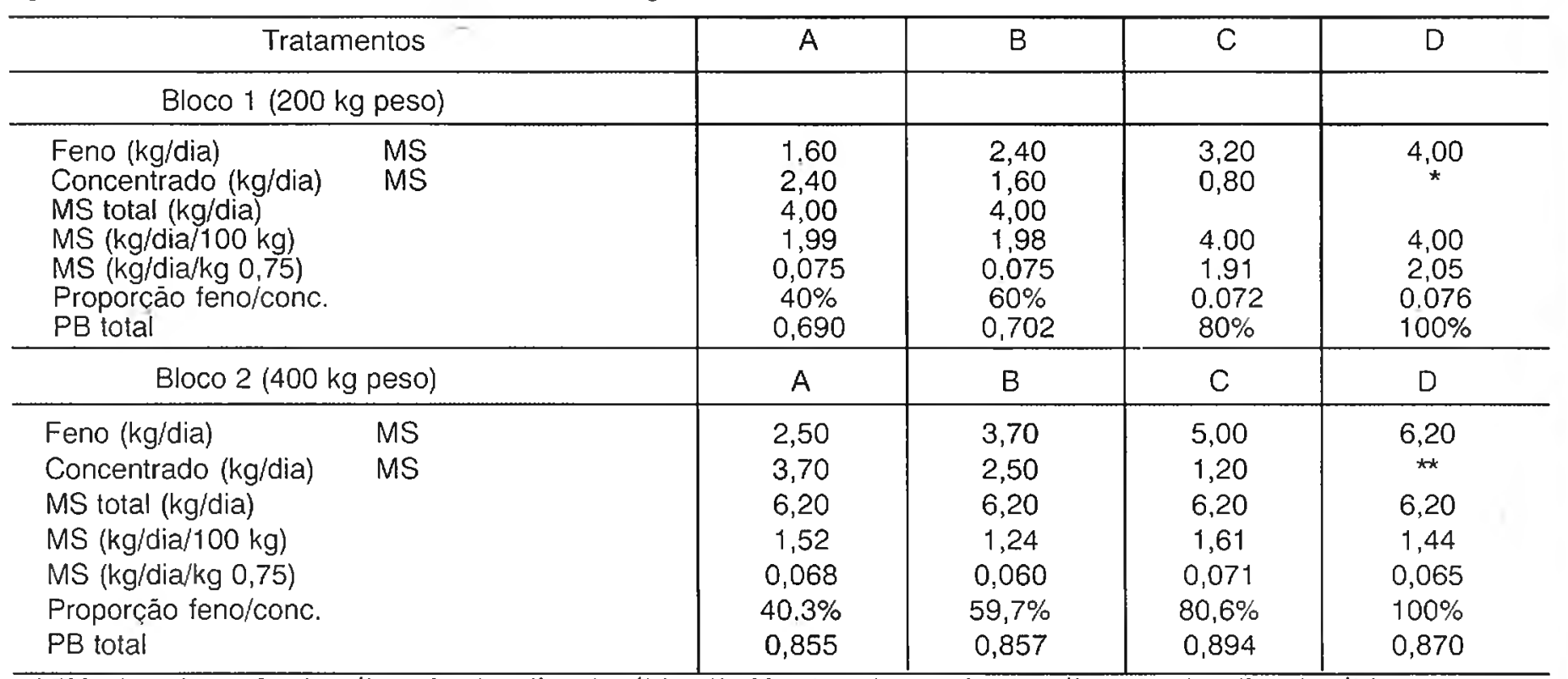

* $500 \mathrm{~g}$ de melaço $+8 \mathrm{~g}$ de uréia $+40 \mathrm{~g}$ de sulfato de cálcio * $500 \mathrm{~g}$ de melaço $+40 \mathrm{~g}$ de uréia $+40 \mathrm{~g}$ de sulfato de cálcio

Tabela 2

Degradabilidade ruminal de MS (\%) e PB (\%) do farelo de soja nos diversos tempos de incubaçāo (h) e cebradabilidade efetiva (p). Pirassununga, 1990.

\begin{tabular}{|c|c|c|c|c|c|c|}
\hline \multirow[t]{2}{*}{ Tempo de incubaçāo } & \multicolumn{4}{|c|}{ Tratamentos } & \multirow[b]{2}{*}{$R(1)$} & \multirow[b]{2}{*}{ Prob. $>\mathrm{F}$} \\
\hline & A & $B$ & $\mathrm{C}$ & $D$ & & \\
\hline $\begin{array}{c}\text { Volumoso } \\
\text { MS }(\%)\end{array}$ & $40 / 60$ & $60 / 40$ & $80 / 20$ & $100 / 0$ & & \\
\hline $\begin{array}{c}0 \\
1,5 \\
3,0 \\
6,0 \\
12,0 \\
24,0 \\
48,0\end{array}$ & $\begin{array}{l}21,70 \\
44,65 \\
50,55 \\
60,72 \\
72,24 \\
77,94 \\
94,37\end{array}$ & $\begin{array}{l}23,44 \\
42,86 \\
49,54 \\
61,49 \\
74,35 \\
85,12 \\
93,83\end{array}$ & $\begin{array}{l}22,35 \\
46,82 \\
54,90 \\
65,53 \\
75,14 \\
88,13 \\
94,06\end{array}$ & $\begin{array}{l}22,40 \\
47,31 \\
51,03 \\
59.89 \\
74,13 \\
87,66 \\
92,52\end{array}$ & $\begin{array}{l}L \\
L \\
L \\
L \\
L \\
L \\
L\end{array}$ & $\begin{array}{c}0,748 \\
0,238 \\
0.544 \\
0,925 \\
0,757 \\
0,015^{\star} \\
0,238\end{array}$ \\
\hline $\mathrm{P}$ & 74,98 & 77,13 & 78,95 & 77,45 & & \\
\hline \multicolumn{7}{|l|}{$\mathrm{PB}$} \\
\hline $\begin{array}{c}0 \\
1.5 \\
3,0 \\
6,0 \\
12,0 \\
24,0 \\
48,0\end{array}$ & $\begin{array}{l}12,10 \\
33.55 \\
40,63 \\
53,11 \\
69,81 \\
81,74 \\
97,50\end{array}$ & $\begin{array}{l}13,54 \\
30,42 \\
40,68 \\
53,07 \\
73,17 \\
87,02 \\
97,30\end{array}$ & $\begin{array}{l}12,11 \\
36,82 \\
48,30 \\
59,44 \\
70,52 \\
90,46 \\
97,41\end{array}$ & $\begin{array}{l}12,11 \\
39,78 \\
42,82 \\
53,01 \\
74,39 \\
90,47 \\
96,89\end{array}$ & $\begin{array}{l}L \\
L \\
L \\
L \\
L \\
L \\
L\end{array}$ & $\begin{array}{l}0,740 \\
0,136 \\
0,589 \\
0,801 \\
0,968 \\
0,057 \\
0,671\end{array}$ \\
\hline $\mathrm{P}$ & 68,41 & 76,04 & 78,02 & 77,60 & & \\
\hline
\end{tabular}

(1) = Regressāo linear $\quad\left(^{*}\right)=p<0,05$ 


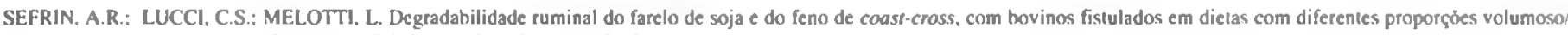
concentrado. Braz. J. vet. Res, anim. Sci. Săo Paulo, v. 34, n.1. p.31-36, 1997.

Tabela 3

Degradabilidade ruminal da MS $(\%)$ e FDN $(\%)$ do feno nos vários tempos de incubaçóo e degradabilldade efetlva "p". Pirassununga, 1990.

\begin{tabular}{|c|c|c|c|c|c|c|}
\hline \multirow{2}{*}{$\begin{array}{l}\text { Tempo de } \\
\text { incubaçāo }\end{array}$} & \multicolumn{4}{|c|}{ Tratamentos } & \multirow[b]{2}{*}{$R(1)$} & \multirow[b]{2}{*}{ Prob. > F } \\
\hline & A & $\mathrm{B}$ & C & $\mathrm{D}$ & & \\
\hline \multicolumn{7}{|l|}{$\begin{array}{c}\text { Volumoso } \\
\text { MS (\%) }\end{array}$} \\
\hline $\begin{array}{c}0 \\
6,0 \\
12,0 \\
24,0 \\
48,0 \\
72,0 \\
96,0\end{array}$ & $\begin{array}{l}13,75 \\
22,81 \\
27,63 \\
35,50 \\
48,17 \\
54,80 \\
58,82\end{array}$ & $\begin{array}{l}13,84 \\
22,27 \\
28,41 \\
40,00 \\
53,53 \\
61,47 \\
64,06\end{array}$ & $\begin{array}{l}14,69 \\
23,29 \\
29,88 \\
42,17 \\
55,03 \\
60,63 \\
64,93\end{array}$ & $\begin{array}{l}12,95 \\
22,48 \\
29,26 \\
40,02 \\
55,20 \\
59,55 \\
61,91\end{array}$ & $\begin{array}{l}L \\
L \\
L \\
Q \\
L \\
Q \\
Q\end{array}$ & $\begin{array}{c}0,678 \\
0,986 \\
0,275 \\
0,024^{\star} \\
0,006^{\star \star} \\
0,007^{\star \star} \\
0,004^{\star \star}\end{array}$ \\
\hline$P$ & 34,50 & 37,16 & 38,58 & 37,66 & & \\
\hline \multicolumn{7}{|l|}{ NDF } \\
\hline $\begin{array}{c}0 \\
6,0 \\
12,0 \\
24,0 \\
48,0 \\
72,0 \\
96,0\end{array}$ & $\begin{array}{l}03,01 \\
06,89 \\
14,63 \\
22,44 \\
38,81 \\
46,36 \\
53,49\end{array}$ & $\begin{array}{l}02,41 \\
07,62 \\
15,88 \\
30,38 \\
46,89 \\
56,81 \\
59,85\end{array}$ & $\begin{array}{l}03,67 \\
09,56 \\
19,66 \\
33,88 \\
48,03 \\
54,76 \\
60,40\end{array}$ & $\begin{array}{l}01,84 \\
05,21 \\
17,03 \\
30,64 \\
47,99 \\
54,98 \\
58,49\end{array}$ & $\begin{array}{l}L \\
Q \\
L \\
Q \\
L \\
Q \\
Q\end{array}$ & $\begin{array}{c}0,555 \\
0,019^{\star} \\
0,173 \\
0,019^{\star} \\
0,009^{\star} \\
0,011^{\star} \\
0,006^{\star}\end{array}$ \\
\hline$P$ & 22,32 & 27,25 & 29,23 & 28,31 & & \\
\hline
\end{tabular}

(1) $\mathrm{R}=$ Regressāo $\left(L=\right.$ linear e $\mathrm{Q}=$ quadrática); $\left({ }^{\star}\right)=p<0,05$

$(\star \star)=p<0,01$

Tabela 4

Valores médios de pH, volume ruminal, turn-over e protozórios totais. Pirassununga, 1990.

\begin{tabular}{|c|c|c|c|c|c|c|}
\hline \multirow{2}{*}{\multicolumn{2}{|c|}{$\begin{array}{l}\text { Tratamentos } \\
\text { volumosos (1) }\end{array}$}} & \multirow{3}{*}{$\begin{array}{c}\mathrm{pH} \\
6,74\end{array}$} & \multirow{3}{*}{$\begin{array}{c}\begin{array}{c}\text { Volume } \\
\text { ruminal (1) }\end{array} \\
89,19\end{array}$} & \multicolumn{2}{|c|}{ Turn-over } & \multirow{3}{*}{$\begin{array}{l}\text { Protozoários } \\
335.767,50\end{array}$} \\
\hline & & & & T.O./h & T.O./dia & \\
\hline A & 40 & & & 0,077 & 1,84 & \\
\hline$B$ & 60 & 6,93 & 72,20 & 0,079 & 1,90 & $440.190,00$ \\
\hline$C$ & 80 & 6,91 & 75,75 & 0,078 & 1,88 & $573.717,50$ \\
\hline$D$ & 100 & 6,90 & 79,84 & 0,085 & 2,03 & $368.688,00$ \\
\hline \multicolumn{2}{|c|}{$\begin{array}{c}\text { Regressão (1) } \\
\text { Prob. > F }\end{array}$} & $\begin{array}{c}L \\
0,193\end{array}$ & $\begin{array}{c}L \\
0,530\end{array}$ & $\begin{array}{c}L \\
0,602\end{array}$ & $\begin{array}{c}\mathrm{L} \\
0,592\end{array}$ & $\begin{array}{c}Q \\
0,00001 \text { (*৯) }^{(\star 2}\end{array}$ \\
\hline
\end{tabular}

(1) $R=$ Regressão $\left(L=\right.$ linear e $Q=$ quadrática); $\left(^{\star \star}\right)=p<0,01$

\section{CONCLUSŌES}

Com base nos resultados da degradabilidade obtidos no presente trabalho, para proporções de $40,60,80$ e 100 de feno na raçāo, as seguintes conclusōes podem ser enumeradas:

1) A degradabilidade da matéria seca do farelo de soja, com 24 horas de incubação ruminal, variou de $77,9 \%$ a $88,1 \%$ e foi maior à medida que se aumentou a porção de volumosos na dieta.

2) A degradabilidade da proteína do farelo de soja, com 24 horas de incubaçāo ruminal, ficou entre $81,7 \%$ e $90,4 \%$ e foi semelhante estatisticamente para todos os tratamentos.

3) A degradabilidade da matéria seca do feno foi menor no tratamento com $40 \%$ de volumoso, em relação aos teores de $60 \%$,
$80 \%$ e $100 \%$, nos tempos de incubação de 24 horas ou mais.

4) A degradabilidade da fibra do feno também foi menor no tratamento com $40 \%$ de volumoso, em relação aos teores de $60 \%, 80 \%$ e $100 \%$, nos tempos de incubação de 24 horas ou mais. 


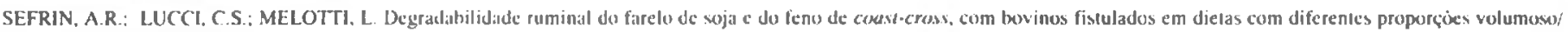
concentrade. Braz. J. vet. Res. anim. Sci. Sảo Paulo, s.-34. n.1. p. 31-36. 1997.

\section{SUMMARY}

This work evaluated ruminal degradabilities of soybean oil meal dry matter (DM) and protein (CP). and of coast-cross hay DM and neutral detergent fiber (NFD), through nylon bag technique in situ. For treatments were used different proportions of roughage in D. M. rations: $A=40 \% ; B=60 \% ; C=80 \%$ and $D=100 \%$ hay. Sixteen steers with rumen canulas were used in a randomized block design with two replicates for each treatment inside blocks, all diets balanced for nitrogen. DM degradability of soybean oil meal with $24 \mathrm{~h}$ of incubation time increased linearly $(p<0.05)$, with higher levels of roughage from $77.9 \%$ to $88.1 \%$. CP degradability of soybean oil meal presented no differences among treatments, with values between $81.7 \%$ and $90.4 \%$ at $24 \mathrm{~h}$ of incubation time. Hay DM and NDF degradabilities showed smaller values $(p<0.01)$ in the lower roughage level $(40 \%)$. Total protozoa concentration in rumen fluid showed quadratic regression $(p<0.01)$, with smallest concentration for the lower roughage level $(40 \%)$.

UNITERMS: Digestibility; Bovine; Fistula; Hay; Soybean meal.

\section{REFERÊNCIAS BIBLIOGRÁFICAS}

I-Al:RC Nutritive Requeriments of Ruminant Animals. Protein Nutrition Abstracts and Reviews, v.62. n.12. p. 787-835. 1992.

2-AOAC - ASSOCIATION OF OHFICIAL AGRICUITTURAI. CHEMISTS Ofricial methods of analysis, I0.ed. Washington D.C.. 1980.

3-BARRIO. J R.: GOETSCH. A.L.: OWENS. F.N. Effect of dietary concentrate on in situ dry matter and nitrogen disappearance of a variety of feedstuffs. Journal of Dairy Science, v.69, n.2, p.42(0-30, 1986.

4.BARRIO. J R.: OWLNS. I.N.: GOETSCH, A.1. Soluble nutrients in protein supplements and in situ disappearance. Canadian Journal of Animal Science, v.65. n.3. p.667-72. 1985

5-BOER, G.: MURPIIY, J.J.: KENNELLIY, J.J. Mobile nylon bag for estimating intestinal availability of rumen undegradable protein. Journal of Dairy Science, v.70, n. . . p. $977-82,1987$.

6-(HIMWANO, A.M.: ORSKOV. E.R.: STEWART, (.S. Effect of dictary proportions of roughage and concentratte on rate of digestion of dried gratsis and celluluse in the rumen of sheep. Proceedings of the nutrition society, v.35, n.2. p. $101 \mathrm{~A}, 1976$.

?-COCHRAN, W.G.; COX. G.M. Experimental designs. New: York, John Wiley. 1957.011p.

8-DEHORITHY. B. Classification and morphology of protozoa. Woosicr. Ohio Agricultural Research \& Development Center. 1977. 82p.

9.1 H.ACHOWSKY. (;.: SCHNEII)ER. M. Inlluence of various straw-10concentrate ratios on in sacco dry matter degradability, feed intake and apparent digestibility in ruminants. Animal Feed Science and Technology. v.38. n 23. p.149.217, 19(9)2.

I1)-(;OE:RING. H.K.: VANSOEST. P.J. Forage fiber analysis (apparatus, reagents, procedures and some applications). Walshington. Agricultural Research Service. 1470. 19p. Agricultural Handbook. 379.

11-HA. J.K.: KENNE.L.LY, J.J. In situ dry matter and prolein degraddation of various protein sources in dairy cattle. Canadian Journal of Animal Science, v.64, n.2, p.44.3-52, 1984

12-IIOPSON. J.D.: JOHINSON, R.R.: DEHORITY. B.A. Evaluation of the dacron technique as a method for measuring cellulose digestibility and rale of forage digestion. Journal of Animal Science. v.22, n.2. p.448-53. 1963.

13-1IYDEN. S. A lurbidemetric method for the determination of higher polvethylene glycols in biological materials. K. Lantbr Hogsk. Arbb. v.22. p.139-45. 1956

14-KENNE:I)Y. D.W. BUNTIN(j. D. Effects of starch or ruminat fermenlation and detergent fiter digestion in lambs fed bernugrass hay. Animal Feed Science and Technology. v.36, n. I. 2, p.91-100, 1992.

15-KIRKPATRICK. B.K.: KENNELLY, J.J. In situ degradability of protein and dry matter from single protein sources and from a total diet. Journal of Animal Science, v.65, n.2. p.567-76. 1987.

I6-I.INIDHER(j. J.E. The effect of sample size and sample structure on the degradation of dry matter, nitrogen and cell walls in nylon bags. Swedish Journal of Agricultural Research, v.11, n.2, p.71-6. I981at.

17-I.INDIBERC, J.L. The effect of hasal diet on the ruminal degradation of dry malter, nitrogenous compounds and cell walls in nylon baggs roughage and cereals in various proportions. Swedish Journal of Agricultural Research. v.11, n.4. p. 159-69, 1981 .

18-LINIDISERG, J.E. Rumen degradation pattern of dry matler and nitrogenous compounds of some concentrates studied with the nylon bag lechnigue.
Swedish Journal of Agricultural Research. v.11, n.4, p.171-6 1981c. 19-LOERCH. S.C.: IBERCIER. L.L.; GIANOLA, D.; FAHEY, (i.C. Jr. Effects of dielary protein source and energy level on in sim nitrogen disappearance of various protein sources. Journal of Animal Science. v. 56. n.1, p.2(16-16.1983.

20-I.UCCI. C.S.: (CONRAD), II R.: 1)EHORI'TY, B.: GRUBB, J.A. Populaçiés microbianas dos rumens de vacas leileiras submetidas a diversas raçoces. Revista da Faculdade de Medicina Veterinária e Zootecnia da Lniversidade de Sáo Paulo. v.19, n.2. p.153-6, 1982.

21-MEHIREZ, A.Z.: ORSKOV. E.R. A study of the artificial fibre bag techniçue for determining the digestibility of feeds in the rumen. Journal of Agricultural Science. v.88, n.3. p. (0.5-50. 1977

22-MEL.OTTI, L.: LUCCI. ('S. Determinaçāo do valor nutritivo de capins: Napier Fino alraves do ensaios de digestibilidade (aparente) com carneiros. Boletion da Indústria Animal. v.26, p.275.84. 196\%.

23-MICHALET-I)OREAU, B.; OUL.D-BAH. M.Y. In viero and in salco methods for estimation of dietary nitrogen degradability. Animal Feed Science and Technology, v.40. n. I. p. 57-86. 1992.

24-MILLER, B.G.; MUNTIFERING, R.B. Effect of forage: concentrate on kinetics of forage fiher digestion in vivo. Journal of Dairy Science. v. 68 , n. 1, p. $4(0-4,1985$.

25-N.R.C. - NATIONAL. RESEARCH COUNCIL. Nutrient requirements of dairy cattle. 6.ed. Washington. National Academy Press, $148 \%$

20-N.C.R. - NATIONAL, RESEARCHI COUNCIL. National requirements of sheep - Washington, D.C.. National Academy Press, 1985

27-ORSKOV. E.R.; HOVEI.L. F.D. dEB.: MOULD. F. Uso de la técnica de la bolsa de nylon para la avaluación de los alimentos. Producción Animal Tropical, v.5, n. 3. p.213.3.3. 1980.

28-ORSKOV, E.R.; McDONAI.D. The estimation of degradability in the rumen from incubation measurements weighed according to ratte of passage. Journal of Agricultural Science. v.92, n.2, p.4(6)-50.3, 1979.

29-PETTT, II.V. In situ degradability of feed ingredients all two proportions of concentrate. Annales de Zootechnie, v.41, n.2. p.14.5-52. 1992.

30-POORE. M.11.: MOORE. J.A.; SWINGLE. R.S. Differential passage ralles and digestion of neutral detergent fiber from grain and forages in 30, 60 and $90 \%$ concentrate diets fed to steers. Journal of Animal Science. v.68, n.9. p.296.5-73.1990.

31-ROBINSON, P.II.: KENNEI.I.Y, J.J. Influence of degradability of suplemental protein and time post-partum in early lactation dairy cows. I Rumen fermentation and milk production. Livestock Production Science, v.28, n.2. p.121-38. 1991 a.

32-RODE. 1..M.: WEAKI.EY. D.C.: SATTER. L.D. Effect of forage amount and particle size in diets of laclating dairy cows on site of digestion and microbial protein synthesis. Canadian Journal of Animal Science. v. 0.5 . p.101-11. 1985

3.3-SUSMEL, P.; STEFANON. 13.; PIASENTIER, E. Effect of forage and a concentrate intake level on rumen degradability of protein sources having different in vifre rates of $\mathrm{N}$ solubilisation. Animal Feed Science and Technology. v.26, n.3,4, p.231-49.1989.

34-THOMPSON. (.: MORAN, J.B. The rate of dry matter disappearance from nylon bags of maize silage/grain diels as influenced by basal ration and processing of lesi simples. Animal Feed Science and Iechnology, v. 16. n.3. p. 225-31, 1996.

35-UDEN. P. The effect of intake and hay: concentrale ratio upon digestibility and digestal passagec. Animal Feed Science and Technology. v. II n..3. 


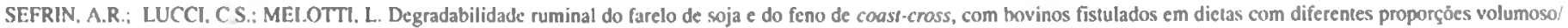
concentrado. Braz. J. ver. Res. anim. Sci. Săo Paulo, v.34, n. I, p.331.36, 1997.

p. 167.79, 1984.

36-WOHLT, J.E.; SNIFFEN. C.J.; HOOVER, W.H. Measuremen! of protein solubility in common feedstuffs. Journal of Dairy Science, v.56, n.8. p. 1052-7, 1973.

37-ZHAO, J.Y.: SHIMOJO. M.; GOTO. I. The effects of feeding level and roughage/concentrate ratio on the measurement of protein degradability of Iwo tropical forages in the rumen of goats, using the nylon bag technique. Animal Feed Science and Technology. v.41, n.4. p.261-9, 1993. 